\title{
Research on College English Writing Teaching from the Perspective of Blended Learning
}

\author{
Shuang Wang \\ Qiqihar Medical University, Qiqihar City, Heilongjiang Province, 161006, China
}

Keywords: College English; Writing Teaching; Blended Learning; Implementation Strategy

\begin{abstract}
In order to improve the achievement of college English writing and optimize the unchanging writing teaching mode, the author put forward the blended teaching mode of college English experiential writing. Based on the author's learning and teaching experience, this paper first analyzed the basic connotation of blended learning, then put forward the construction and implementation strategies of blended learning model, and finally summarized the remaining problems in the teaching of college English writing from the perspective of blended learning.
\end{abstract}

\section{Introduction}

English writing is an essential skill for college students. However, the traditional teaching mode of English writing can not effectively improve the students' vocabulary, grammar and discourse structure. As a result, the following problems exist in the teaching of English writing: First, teachers and students do not pay enough attention to the teaching and learning of English writing; second, students lack sufficient and effective English language input, which leads to poor content and unreasonable structure of English writing; third, the teaching mode of writing is single, which make it hard effectively teach students according to their aptitude; fourth, the teaching of writing is difficult because of the limited class hours, and the students generally have difficulties in choosing sentences, layout of the text and writing skills. With these problems in writing teaching, the author made a further study on the application of blended learning in college English writing teaching based on the research on blended learning proposed by researchers at home and abroad in foreign language teaching. This paper tries to construct an effective blended learning model for college English writing teaching in order to improve students' English writing level.

\section{Basic Connotation of Blended Learning}

Blended learning theory. Blended Learning is a new teaching mode which integrates face-to-face teaching and online learning. Professor Hekekang said: "blended learning combines the advantages of traditional learning with digital or networked learning. That is to say, teachers should not only give play to the leading role of teachers in guiding, enlightening and monitoring the teaching process, but also fully reflect the initiative, enthusiasm and creativity of students in the learning process. "As a matter of fact, blended learning is a teaching mode of teacher-led and student-centered, which combines various learning models, learning methods, learning contents and learning environments. It emphasizes the organic combination of teacher's leading role and student's main position in teaching process. Blended learning makes classroom face-to-face teaching and online learning complement each other, and helps to obtain the best teaching effect and the best learning effect.

\section{The Construction and Implementation Strategies of Blended Learning Model}

\subsection{Construction of blended learning model}

By analyzing the characteristics, advantages and disadvantages of the traditional teaching mode and the network teaching, the author integrates the two teaching models with each other's advantages, and designs the blended learning model of college English writing(figure 1). The model 
integrates the elements of constructivism teaching view: First, integrate the teaching methods of writing, pay attention to the characteristics of language and structure of writing in different genres and emphasize the importance of the writing process. Second, integrate the teaching mode of teaching inside and outside the classroom to form self-study and face to face teaching. Third, integrate multimedia and network technology to optimize the teaching environment of English writing. In the blended learning mode of English writing, the teacher's role is transformed into a mentor, participant and helper in the learning process, who is responsible for arranging writing tasks, introducing writing strategies, grouping students according to their English foundation, guiding and participating in group discussions, evaluating final work, feedback information and non-real-time interaction with students via E-mail or Blog channels.

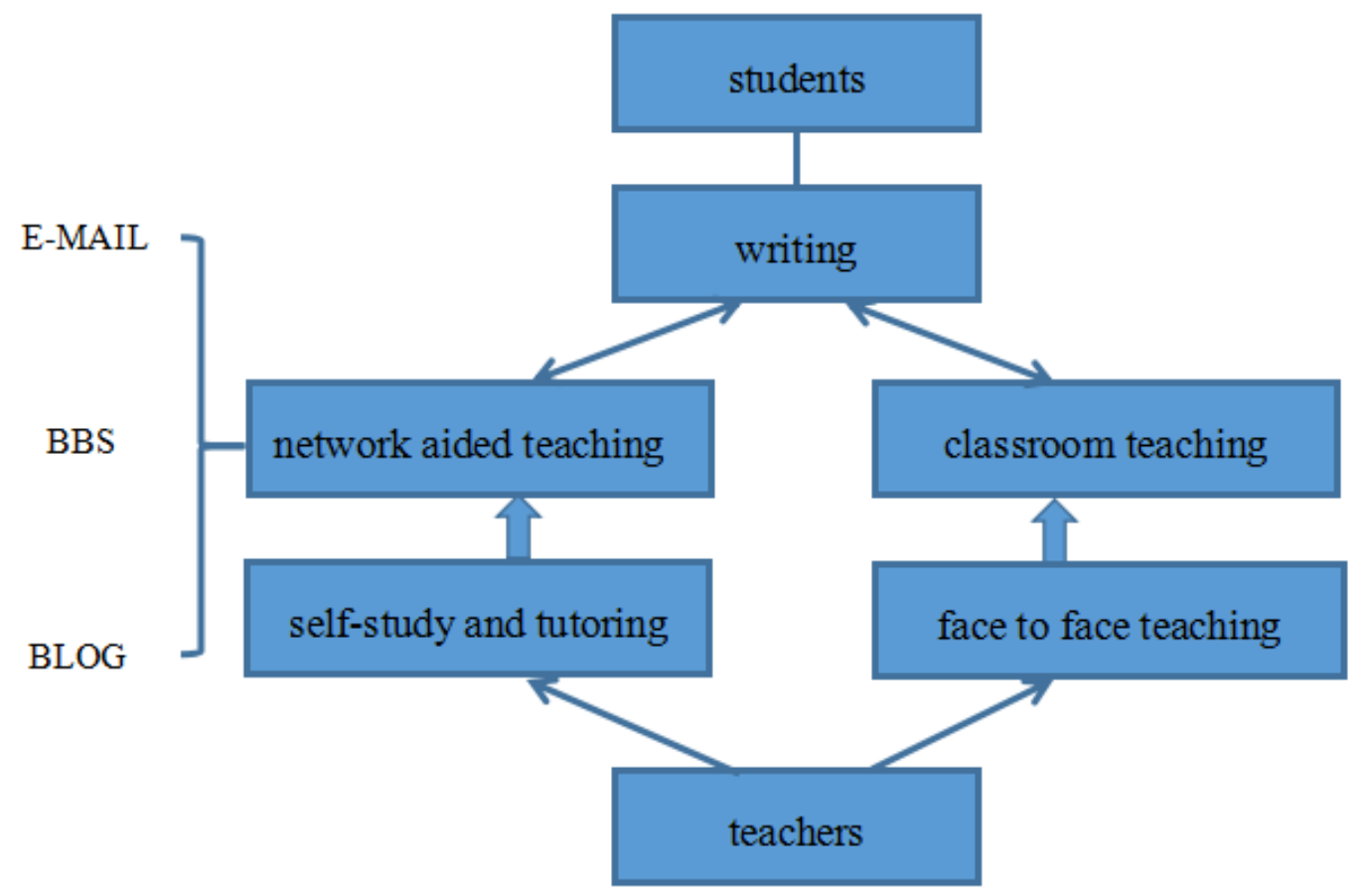

Fig. 1 Blended learning model of college English writing

\subsection{The implementation of blended learning model in English writing}

The interaction between students and teachers in blended learning is shown in figure 2 . According to the model, there are three stages in the process of interaction between students and teachers: (1) Preparatory phase. In the pre-writing preparation phase, the teacher should design writing topics for students, assign reading and discussion tasks according to the topic or scene involved, and provide online writing skills guidance. According to the tasks assigned by the teacher, the students would collect information, read the relevant materials, determine the main questions to be written, list out the outline, draft the preliminary draft, and finally discuss the writing content in groups. In the process, a teacher can do some teaching aids, such as making courseware for writing skills, students' model articles, etc., to facilitate classroom communication, and linking together what students should learn or what they have learned for students to carry out extended learning. Teachers should provide different levels of relevant background materials, basic knowledge and so on, so that students can extract learning content according to their own needs.

Teachers would provide different levels of relevant background materials, basic knowledge and so on, so that students can extract learning content according to their own needs. At the writing stage, students prepare drafts for teachers and peers to read and revise. Students can communicate with teachers or peers synchronously or asynchronously through E-mail, QQ and Blog. Teachers and peers can make suggestions or amendments to students' works. In addition, with the help of computer word processing programs, students are guided to make self-revision of grammar and spelling, and the procedures for modifying and editing are simplified, thus reducing the burden of teachers' correction. It also enables students to focus more on words and creative writing. In the 
revision stage, teachers and peers determine whether students' works are correct, coherent, clear and accurate. The whole process includes peer feedback, teacher feedback, feedback between teachers and students, and students' revision and final draft according to feedback and suggestions. In this stage, teachers should set aside some time for face-to-face tutoring to help students solve the problems of composition form and content encountered in the process of revision. During the implementation of this model, we should pay attention to several key links, such as assignment, grouping, collaborative learning, submission of works, communication and feedback, and submission of manuscripts.

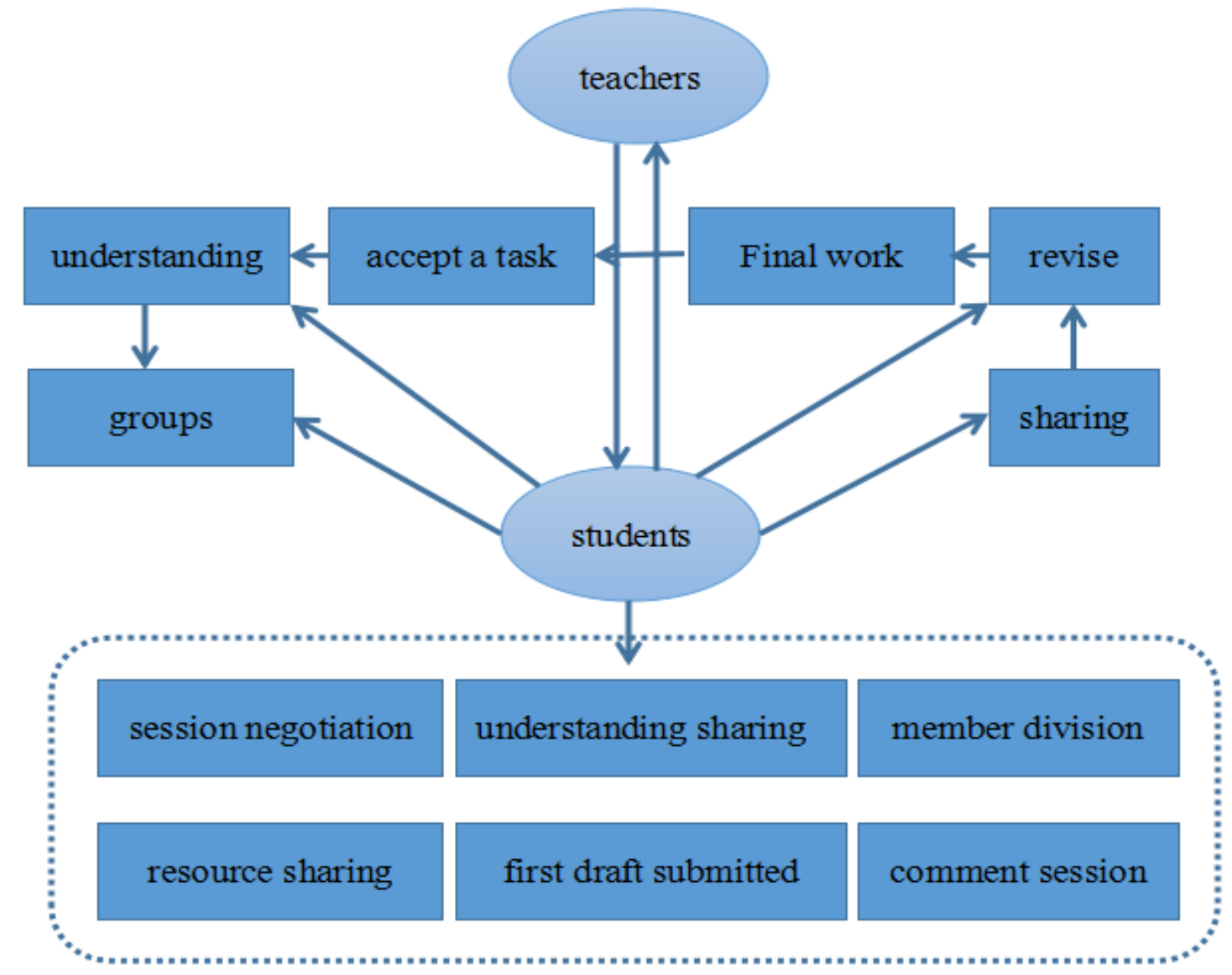

Fig. 2 Interaction between students and teachers in blended learning

\section{Problems in Blended College English Writing Teaching}

At present, there are still some problems to be solved in the implementation of English writing teaching. First of all, the QQ platform has not been able to monitor students' learning behavior effectively. After the publication of the learning materials, they can only check the download capacity, and they cannot accurately know the situation of students' learning and mastering the materials. In the case of teaching in large classes, inevitably, there will be gaps in the collection of relevant learning records, which would affect the accuracy and fairness of the evaluation. In addition, although the online automatic marking network has certain pertinence to the quantitative score of writing tasks, the evaluation feedback is mainly focused on the use of vocabulary and sentence structure, so, sometimes there are errors in correcting. For the students' universal structure, the evaluation on the problem of thinking is not sufficient, and the advice is very few. The pressure of teachers' correction not only still exists, but also adds the task of explaining to students the difference between automatic system and manual correction. Sometimes the difference between the two grades can confuse students. Finally, there are some problems for teachers and students to use online education platform, such as cumbersome registration and difficulties in obtaining high-quality curriculum resources. Because the online education platform needs user input personal information registration before using, so, the time consumption of this link makes them doubt the 
convenience of online learning. In addition, free online course resources are limited, some excellent resources need to pay a fee to read.

\section{Summary}

The application of blended learning in college English writing teaching can show respect for different students' learning styles, provide students with more abundant learning resources and create a diversified learning environment. In view of the problems faced by blended college English teaching, the author suggests the development and construction of a college English teaching platform, to make up for the deficiency of the existing learning platform. It provides more and more teaching resources that meet the needs of individualized learning, strengthens the monitoring and management of students' English writing learning process, and provides sufficient support in creating a diversified online interactive environment and perfecting various evaluation functions.

\section{Acknowledgement}

Subject Source: Research on Blended Learning in the Context of "Internet +" in 2018, Education Management Information Center of the Ministry of Education.

Title of the project: Research on College English Writing Teaching based on Blended Learning Subject number: EIJYB2017-143

\section{References}

[1] Huang Yurong. A study on the feedback of College English Teachers' Writing Evaluation under the blended Teaching Mode [J]. Journal of Beijing Institute of Printing, 2018, 26(01): 153-156.

[2] Zhou Yuyan. A study of Strategies for improving College English Writing Self-efficacy [J]. Journal of Heihe university, 2017, 8(05): 144-145.

[3] Shi Shugui, Tao Weitian, an QianRu, Muxiu Rong, Li Zhaorui. Blended Teaching: a New Exploration of College English Writing Teaching [J]. Gansu science and technology, 2016, 32(11): 83-85.

[4] Meng Yanli. A study on the cultivation of College English Writing Self-efficacy based on blended Teaching [J]. Research on Audio-visual Education, 2011, (05): 96-101.

[5] Hou Jianjun. Practice and Research of College English Teaching based on blended Learning [J]. Research on Audio-visual Education, 2010, (05): 108-111. 